\title{
Oncogenic KRAS is not necessary for Wnt signalling activation in APC-associated FAP adenomas
}

\author{
Antònia Obrador-Hevia,' Suet-Feung Chin, ${ }^{2}$ Sara González, ${ }^{3}$ Jonathan Rees, ${ }^{4}$ Felip Vilardell, ${ }^{3}$ Joel K Greenson, ${ }^{5}$ \\ David Cordero, ${ }^{3}$ Víctor Moreno, ${ }^{3}$ Carlos Caldas ${ }^{2}$ and Gabriel Capellá3* \\ I Cancer Cell Biology Group, Institut Universitari d'Investigació en Ciències de la Salut (IUNICS) — Universitat de les Illes Balears, Mallorca, Illes \\ Balears, Spain \\ ${ }^{2}$ CRUK Cambridge Research Institute. Li Ka Shing Centre. Robinson Way, Cambridge CB2 ORE, UK \\ 3 Laboratori de Recerca Translacional, Departament de Prevenció i Control del Càncer, Servei d'Epidemiologia i Registre del Càncer, \\ IDIBELL — Institut Català d'Oncologia, L'Hospitalet de Llobregat, Barcelona, Spain \\ ${ }^{4}$ Department of Colorectal Surgery, Gloucestershire Royal Hospital, Gloucestershire Hospitals NHS Foundation Trust, Great Western Road, \\ Gloucester, UK \\ ${ }^{5}$ Department of Pathology, University of Michigan Heath System, Ann Arbor, USA
}

*Correspondence to: Gabriel Capellá, Laboratori de Recerca Translacional, Institut Català d’Oncologia, Barcelona, Spain e-mail: gcapella@iconcologia.net

\begin{abstract}
Recent studies have suggested that APC loss alone may be insufficient to promote aberrant Wnt/ $\beta$-catenin signalling. Our aim was to comprehensively characterize Wnt signalling components in a set of APC-associated familial adenomatous polyposis (FAP) tumours. Sixty adenomas from six FAP patients with known pathogenic APC mutations were included. Somatic APC and KRAS mutations, $\beta$-catenin immunostaining, and qRT-PCR of APC, MYC, AXIN2 and SFRP1 were analysed. Array-comparative genomic hybridization (aCGH) was also assessed in 26 FAP adenomas and 24 paired adenoma-carcinoma samples. A somatic APC alteration was present in 15 adenomas ( $\mathrm{LOH}$ in 11 and four point mutations). KRAS mutations were detected in 10\% of the cases. APC mRNA was overexpressed in adenomas. MYC and AXIN2 were also overexpressed, with significant intra-case heterogeneity. Increased cytoplasmic and/or nuclear $\beta$-catenin staining was seen in $94 \%$ and $80 \%$ of the adenomas. $\beta$-Catenin nuclear staining was strongly associated with MYC levels ( $p$ value 0.03 ) but not with KRAS mutations. Copy number aberrations were rare. However, the recurrent chromosome changes observed more frequently contained Wnt pathway genes ( $p$ value 0.012). Based on $\beta$-catenin staining and Wnt pathway target genes alterations the Wnt pathway appears to be constitutively activated in all APC-FAP tumours, with alterations occurring both upstream and downstream of APC. Wnt aberrations are present at both the DNA and the RNA level. Somatic profiling of APC-FAP tumours provides new insights into the role of APC in tumourigenesis.

Copyright () 2010 Pathological Society of Great Britain and Ireland. Published by John Wiley \& Sons, Ltd.
\end{abstract}

Keywords: colorectal cancer; familial adenomatous polyposis; APC; genomic profiling; Wnt signalling

Received 22 July 2009; Revised 29 December 2009; Accepted 2 January 2010

No conflicts of interest were declared.

\section{Introduction}

Classical familial adenomatous polyposis (FAP) is most often caused by truncating germline mutations typically located in the central region of the Adenomatous Polyposis Coli $(A P C)$ tumour suppressor gene [1]. In some cases, missense mutations can also occur [2,3]. APC is also somatically mutated in sporadic colorectal cancer (CRC) at a high frequency. APC mutations can be detected in aberrant crypt foci, suggesting that the loss of APC function represents an initiating event in CRC [4]. Inactivation of both $A P C$ alleles is both necessary and sufficient to promote adenoma growth [5].

Molecular analyses of FAP-associated tumours have provided deep insights into tumourigenesis. Biallelic mutation of the APC gene is a hallmark of the colorectal, duodenal, and desmoid tumours that develop in FAP patients. The site of the 'first hit' in the $A P C$ tumour suppressor gene determines the type of the 'second hit'. Mutations near codon 1300 [codons 1285-1378; in the mutation cluster region (MCR)] [6] are associated with loss of heterozygosity (LOH), with no loss of genetic material [7]. More recently, putative 'third hits', mostly copy number gains or deletions, have been reported [8]. Combined profiling of mouse and human adenomas has allowed the identification of new direct and indirect target genes such as $B U B 1$, $M A D 2 L 1$, and $C D 44$, which are associated with APCdriven tumour progression [9-14].

The APC protein plays an integral role in the Wnt signalling pathway, as it binds and down-regulates $\beta$ catenin [15] by the formation of a protein complex 
Table 1. Clinical characteristics of patients included in the study

\begin{tabular}{|c|c|c|c|c|c|c|c|}
\hline ID & Sex & $\begin{array}{l}\text { Family } \\
\text { history }\end{array}$ & $\begin{array}{l}\text { Age at operation } \\
\text { (years) }\end{array}$ & $\begin{array}{c}\text { No of } \\
\text { adenomas }\end{array}$ & $\begin{array}{l}\text { Extracolonic } \\
\text { disease }\end{array}$ & CHRPE & Germline $A P C$ mutation \\
\hline FAP1 & $F$ & Yes & 35 & 300 & No & No & $\begin{array}{l}\text { c. } 1958+1 \mathrm{G}>\mathrm{A} ; \text { r. }\left[=, 1744 \_1958 \mathrm{del}\right] \\
\text { p.? }\end{array}$ \\
\hline FAP3 & M & No & 41 & $>100$ & No & No & $\begin{array}{l}\text { c. }[1958+3 A>G ; 1959 G>A] ; \quad \text { r. }[=\text {; } \\
\text { 1744_1958del; 1959G>A]; p.? }\end{array}$ \\
\hline FAP4 & M & No & 26 & $>1000$ & Yes & No & c. $4175 C>A ;$ p.Ser1392X \\
\hline FAP6 & M & No & 23 & $>100$ & Yes & No & c.4612_4613delGA; p.Glu1538llefsX5 \\
\hline FAP8 & $\mathrm{F}$ & Yes & 20 & 139 & No & No & c.1262_1263delinsAA; p.Trp412X \\
\hline FAP9 & $\mathrm{F}$ & Yes & 33 & 800 & No & No & c.3183_3187del; p.GIn1062X \\
\hline
\end{tabular}

$\mathrm{F}=$ female; $\mathrm{M}=$ male; $\mathrm{CHRPE}=$ congenital hypertrophy of the retinal pigment epithelium.

with AXIN and glycogen synthase kinase-3 $\beta$ (GSK3- $\beta$ ) [16]. Loss of functional APC, usually due to truncating mutations that remove the $\beta$-catenin regulatory domain, leads to nuclear accumulation of $\beta$-catenin [15], where it acts as a TCF4 transactivator. TCF4 transcriptionally targets pro-proliferative genes such as $M Y C$ and cyclin D1, which are key effectors of this pathway $[17,18]$. The activated $\beta$-catenin/TCF4 complex imposes a progenitor-like phenotype in colorectal cells by regulating MYC and p21 activities [19]. Wnt signalling is autoregulated at many levels. The expression of a variety of positive and negative regulators of the pathway, such as FRIZZLEDs, LRP and HSPG, AXIN2 and TCF/Lef, is controlled by the $\beta$ catenin/TCF complex. Recent studies have suggested that APC loss alone may be insufficient to promote aberrant $\mathrm{Wnt} / \beta$-catenin signalling and that APC and KRAS play distinct roles in the control of stability and nuclear accumulation of $\beta$-catenin [20].

The aim of this study was to gain further insight into the role of APC and the Wnt signalling members in APC-FAP adenomas. We collected FAP adenomas and corresponding mucosae and CRC samples, and screened the APC gene as well as KRAS. We also studied the expression and DNA copy number changes of key members of the pathway both downstream and upstream of APC.

\section{Materials and methods}

\section{FAP colorectal adenomas}

Fresh samples from colectomy specimens of six FAP patients who harboured $A P C$ pathogenic germline mutations were collected before fixation and cryopreserved (Table 1). Ten adenomas representative of the five areas of the colon and rectum (caecum, ascendant, transverse, descendant colon, and rectum) and paired normal mucosa from each patient were analysed. Adenomas were classified according to size as small, $<10 \mathrm{~mm}$; medium, 10-20 mm; or large, $>20 \mathrm{~mm}$ (Supporting information, Supplementary Table 1). A set of ten paired normal mucosa/adenoma/carcinoma samples was also analysed. In all cases, at least $70 \%$ of tumour cell content was present. Written informed consent was obtained from all patients participating in the study. The study protocol was approved by the Ethics Committee of the Hospital Universitari de Bellvitge.

\section{$A P C$ and KRAS mutations}

$A P C$ and KRAS mutations were analysed by sequencing. Genomic DNA was extracted with the QIAamp DNA Mini Kit (QIAGEN Inc, Valencia, CA, USA). $A P C$ primers were designed to amplify $838 \mathrm{nt}$ that contained codons 1203-1482 of the gene and for $K R A S$ a $241 \mathrm{nt}$ fragment containing codons 12 and 13 (Supporting information, Supplementary Table 2). The PCR products were then purified with the Jetquik PCR purification kit (Genomed, Kent, UK) and directly sequenced using ABI PRISM 37.30 (Applied Biosystems Inc, Foster City, CA, USA).

\section{APC $\mathrm{LOH}$ analysis}

$\mathrm{LOH}$ at $A P C$ was analysed using three microsatellite markers on chromosome 5q (D5S82, D5S346, and D5S299) (Supporting information, Supplementary Table 2). Primers are available upon request. Products were detected using ABI PRISM 37.30 (Applied Biosystems Inc). In informative cases, the values given for the peak area of the two alleles in the paired normal and tumour samples were used to define allele loss as described by Cawkwell et al [21]. A ratio of less than or equal to 0.30 was assigned to be indicative of loss on the basis that some tumours in the series contained up to $30 \%$ of normal cells contamination.

\section{APC allele-specific expression (ASE) analysis}

ASE at APC was analysed using the rs2229992 SNP on cDNA (Supporting information, Supplementary Table 2). To specifically amplify cDNA, we used an exon 11 forward primer (5'-GGGACTACAGGCCATT GCA-3') and a reverse primer targeting the exon 1112 junction (5'-ATAGAGCATAGCGTAGCCTTGTT G-3'). PCR products were purified using illustraTM GFXTM PCR DNA and the Gel Band Purification Kit (GE Healthcare, Little Chalfont, UK.). For the single nucleotide primer extension reaction, primer extension was carried out with the SNaPshot Multiplex Kit (Applied Biosystems) with 5'-TATTGCAAGTGGACT GTGAAATGTA-3' according to the manufacturer's instructions. 
Table 2. APC alterations in FAP adenomas

\begin{tabular}{|c|c|c|c|c|c|c|}
\hline \multirow[b]{2}{*}{ ID } & \multicolumn{4}{|c|}{ Somatic } & \multicolumn{2}{|c|}{$A P C$ expression levels } \\
\hline & $\begin{array}{c}\text { Point } \\
\text { mutation* }\end{array}$ & $\mathrm{LOH}$ & $\begin{array}{l}\text { aCGH } \\
\text { loss }\end{array}$ & Total & $\begin{array}{l}\text { Normal } \\
\text { mucosa }^{+}\end{array}$ & $\begin{array}{l}\text { Adenomas with } \\
\text { underexpression }^{\ddagger}\end{array}$ \\
\hline FAP1 & 0 & 5 & $4(3)^{5}$ & $6 / 10(60 \%)$ & 1.676 & $9 / 10$ \\
\hline FAP3 & 1 & 0 & 1 & $2 / 10(20 \%)$ & 0.977 & $3 / 10$ \\
\hline FAP4 & 0 & 3 & 0 & $3 / 10(30 \%)$ & 1.576 & $4 / 10$ \\
\hline FAP6 & 0 & 2 & 0 & $2 / 10(20 \%)$ & 1.932 & $9 / 10$ \\
\hline FAP8 & 1 & 0 & 0 & $1 / 10(10 \%)$ & 0.634 & $0 / 10$ \\
\hline FAP9 & 2 & 1 & 0 & $3 / 10(30 \%)$ & 0.775 & $4 / 10$ \\
\hline
\end{tabular}

* The somatic point mutations detected were as follows: FAP3 AD2: Q1338X C>T; FAP8 AD7: EI397X G>T; FAP9 ADI: SI356XC>G; AD4: EI309X G>T.

† Basal expression refers to $\log _{2}$ values of macroscopically normal mucosa versus a pool of normal colonic mucosa from sporadic colorectal cancer cases.

¥ Underexpression in adenomas is defined as $\log _{2}$ values $<0$ when compared with corresponding normal mucosa of the same FAP patient.

$\S$ In parentheses, cases with concomitant $\mathrm{LOH}$ and loss of genetic material as assessed by aCGH.

SNaPshot reaction products were treated with $1 \mathrm{U}$ of shrimp alkaline phosphatase (usb) for $60 \mathrm{~min}$ at $37^{\circ} \mathrm{C}$ and then for $15 \mathrm{~min}$ at $75^{\circ} \mathrm{C}$. Products were run in an ABI Prism 3130 DNA sequencer and analysed by GeneMapper v4.0 (Applied Biosystems).

ASE was measured using peak intensities in heterozygous samples. Allelic frequencies were calculated as freq $\mathrm{C}=\mathrm{C} /(\mathrm{C}+k \mathrm{~T})$ or freq $\mathrm{T}=\mathrm{T} /\left(\mathrm{T}+k^{\prime} \mathrm{C}\right)$, where $k$ and $k^{\prime}$ are constants given by the mean of the $\mathrm{C} / \mathrm{T}(k)$ and $\mathrm{T} / \mathrm{C}\left(k^{\prime}\right)$ proportions in control samples. ASE values are expressed as the proportion of frequencies of both alleles (freq $\mathrm{C} /$ freq $\mathrm{T}$ ) and are normalized using two normal mucosae from sporadic patients. Three independent replicates of all experiments were obtained and in every experiment a set of controls was included. A Mann-Whitney test was used to evaluate ASE differences among groups.

\section{$\beta$-Catenin immunostaining}

Five-micrometre sections of biopsy specimens were treated with $3 \%$ formaldehyde. After blocking with $3 \%$ hydrogen peroxide, the sections were incubated with the anti- $\beta$-catenin monoclonal antibody (BD Biosciences, San Jose, CA, USA) diluted 1:90 in PBS, followed by washing. Sections were incubated with the anti-mouse EnVision HRP System (Dako, Glostrup, Denmark), followed by washing. Results were independently analysed by two pathologists who assessed the localization and the level of $\beta$-catenin expression. $\beta$ Catenin staining was graded as none, weak, moderate, or strong $(-,+,++,+++)$ for both cytoplasmic and nuclear.

\section{Gene expression analysis}

Total RNA was isolated using Trizol ${ }^{\circledR}$ Reagent (Invitrogen, Carlsbad, CA, USA). One microgram of RNA was reverse-transcribed into cDNA using pdN6 primers and MMLV reverse transcriptase (Invitrogen). Subsequent real-time PCR reactions were performed in duplicate in the LightCycler ${ }^{\circledR} 2.0$ System (Roche Diagnostics, Mannheim, Germany) using the SYBR Green detection methodology. Primers were designed to specifically amplify $M Y C, S F R P 1$, and AXIN2 mRNA as they were placed in different exons of the genes
(Supporting information, Supplementary Table 2). APC primers targeted exons 2 and 3 , allowing the simultaneous analyses of all transcripts. $\beta-2$-microglobulin was used as an internal control for normalization. Threshold cycle data were analysed using the following formula

$$
\begin{aligned}
\text { ratio }= & \left(\left(E_{\text {target }}\right)^{\Delta C P_{\text {target }}(\text { control-sample })}\right) / \\
& \left(\left(E_{\text {ref }}\right)^{\Delta C P \text { ref }(\text { control-sample })}\right)
\end{aligned}
$$

[22] to quantify the level of gene expression changes. Expression levels were $\log _{2}$ ratios. The $t$ test and Wilcoxon test were applied to $\log _{2}$ ratios to evaluate their significance. The $\log _{2}$ ratios also allowed indirect comparisons between sporadic and FAP mucosae and tumours.

\section{Array CGH analysis}

DNA was isolated as previously described and quantified. DNA labelling was performed using the BioPrime DNA labelling kit reagents (Invitrogen) and according to protocols described elsewhere [23]. Labelled DNAs were hybridized to customized oligonucleotide microarrays containing 3000060 -mer oligo probes assessing 449 chromosomal regions [23]. Fluorescence ratios of scanned images of arrays were obtained using BlueFuse version 3.2 (BlueGnome).

Array CGH data consist of the log ratios of normalized intensities, indexed by the physical location of the probes on the genome. Data were processed using the statistical package snapCGH ( $\mathrm{R}$ package version 1.10.0) of Bioconductor [24] in the $R$ software (http://www.R-project.org) and initially filtered for low-quality probes based on quality standard values. Each microarray was normalized focusing the median intensity in 0 . Values were log-transformed and then the complete set of microarrays was normalized using the quantiles method. Default parameters of snapCGH were used for the segmentation process using the GLAD method [25,26] based on the adaptive weights smoothing (AWS) procedure. Each chromosome of each sample was processed separately and altered regions were compiled from different arrays. 
Array CGH raw data may be found in the Supporting information.

\section{Results}

\section{APC somatic alterations in FAP adenomas}

A somatic APC alteration was present in 15 of 60 $(25 \%)$ adenomas analysed. LOH was detected in 11 out of 60 adenomas (18\%) (Figure 1A and Table 2). In agreement with previous studies [25,26], concomitant loss of genetic material associated with $\mathrm{LOH}$ was observed in three cases only. Mutational analysis of somatic alterations in the $A P C$ gene was directed to the MCR. Only four somatic mutations were detected in the 60 adenomas studied (6\%) (Figure 1B) and these were all nonsense mutations near to codon 1300, one of them being a $\mathrm{C} \rightarrow \mathrm{T}$ transition and the remaining being transversions. In two adenomas, two somatic alterations were detected.

\section{APC mRNA overexpression is present in FAP adenomas}

$A P C$ levels of each FAP adenoma were compared with their corresponding mucosa. Adenomas from all FAP patients presented increased $A P C$ expression levels (three-fold average) (Figure 1C). These changes were not observed in sporadic samples (adenomas and carcinomas) (Figure 1C). Macroscopically normal mucosa from FAP patients showed a 2.4-fold increase when compared with a pool of sporadic normal mucosae, indicating that abnormal overexpression is a very early event in APC-driven tumourigenesis. Altogether, APC RNA expression levels appeared elevated in FAP adenomas compared with sporadic adenomas ( $p$ value $0.0004, t$-test).

Allele-specific expression (ASE) was explored in FAP3 tumours since it turned out to be heterozygous for rs2229992. The range for normal ASE (0.8-1.2) was established using colorectal normal mucosae. While FAP mucosa showed balanced expression of both alleles (0.826), ASE imbalance was present in four (values for individual adenomas: 0.691, 0.589, 0.561, and 0.349) of the five FAP adenomas analysed, suggesting that expression of the mutated allele can be selected for during tumour progression.

Wnt pathway is activated in adenomas and changes in expression occur upstream and downstream of APC

In FAP adenomas, some type of cytoplasmic $\beta$-catenin accumulation was present in 56 of 59 (94\%) cases (Table 3). Nuclear accumulation was observed in 46 of $59(80 \%)$ FAP adenomas but in none of the normal mucosae. Intensities of cytoplasmic and nuclear staining were positively correlated ( $p$ value 0.016 ; Fisher's exact test) (Figure 2 and Supporting information, Supplementary Table 1). The intensity of nuclear $\beta$-catenin staining correlated with adenoma size. Sixteen of 45 $(35 \%)$ small adenomas (less than $1 \mathrm{~cm}$ ) showed moderate to strong nuclear immunostaining $(++$ or +++$)$, while this percentage increased to $78 \%$ (11 of 14) for adenomas larger than $1 \mathrm{~cm}(p=0.006)$. Ten of the 15 cases $(66 \%)$ showing biallelic $A P C$ inactivation showed either moderate $(n=7)$ or strong $(n=3)$ nuclear staining. There was no evidence of heterogeneity in this set of samples. Immunohistochemistry of sporadic samples showed nuclear staining in four of four adenomas and in eight of ten carcinomas.

To extend our studies to other Wnt-related genes, we examined the 60 matched sets of FAP adenomas together with ten sporadic adenomas and ten sporadic carcinomas for expression of CMYC, AXIN2, and SFRP1 (Figure 3). This analysis revealed upregulation of $C M Y C$ in both sporadic (4.34-fold) and FAP tumours (5.82-fold). A statistically significant correlation was observed between $\beta$-catenin nuclear staining and elevated $C M Y C$ levels ( $p$ value 0.03; Kruskal-Wallis test). Furthermore, AXIN2 (also known as conductin) was overexpressed in all the analysed adenomas (11.2-fold). CMYC and AXIN2 expression levels correlated highly with those of $A P C$ ( $p$ value 0.02 and $<0.0001$, respectively; Pearson correlation test). In contrast, SFRPI was consistently down-regulated or even undetectable in FAP (19.5fold) and sporadic tumours (45-fold). Moreover, MYC and SFRPI had altered expression levels not only in tumoural samples, but also in macroscopically normal mucosa (data not shown).

\section{KRAS mutations are rare and are not associated with $\beta$-catenin nuclear accumulation}

Six out of $60(10 \%)$ FAP adenomas were carriers of a KRAS codon 12 mutation (Table 3 and Supporting information, Supplementary Table 1). The most frequent change (G-to-A mutation in the second position of codon 12) was identified in two of the adenomas with KRAS mutations. No correlation was observed between the presence of the mutation and $\beta$-catenin nuclear accumulation (Table 3 ).

\section{Recurrent chromosome changes more commonly contain Wnt pathway genes}

aCGH was performed in 29 of the 60 FAP adenomas and in 24 paired adenoma-carcinoma samples (Figure 4). We explored whether Wnt pathway components and their targets $(n=130)$ were overrepresented in areas with genomic losses or gains. FAP and sporadic samples were jointly analysed. Wnt genes were overrepresented in those areas showing copy number variation ( $p=0.01 ; p=0.01$, Fisher's exact test and Pearson's chi-squared test, respectively). The Wnt genes present in most frequently gained regions were GJB6 (gap junction protein, beta 6), FGF9 (fibroblast growth factor 9), TNFRSF19 (tumour necrosis factor receptor superfamily, member 19), POSTN (periostin), TNFSF 11 [tumour necrosis factor (ligand) 
A

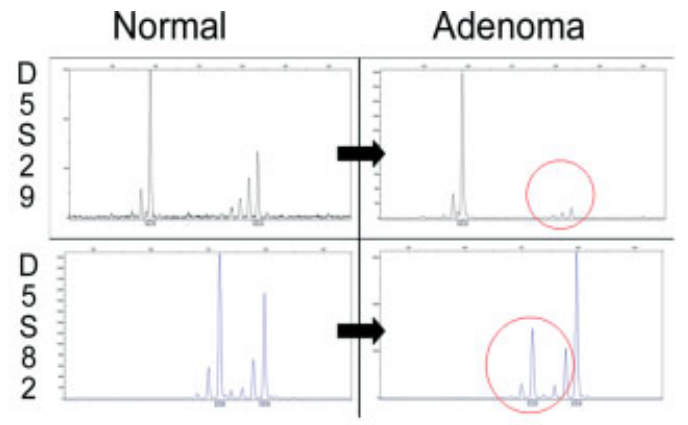

B

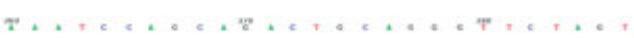

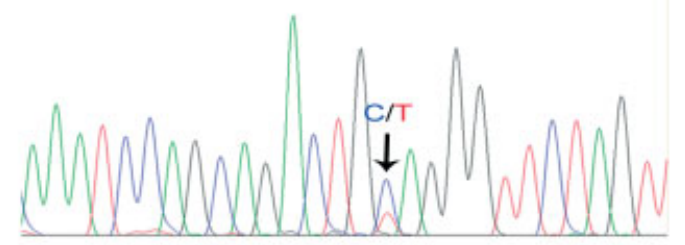
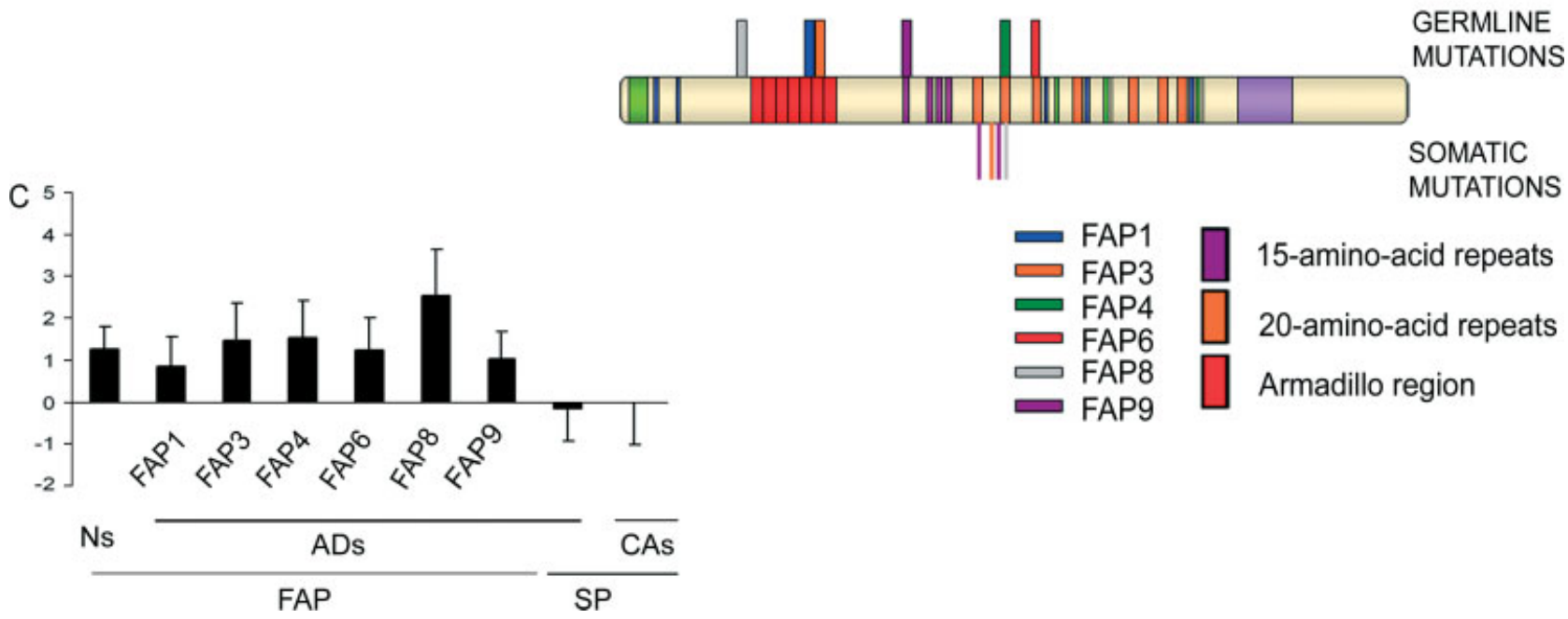

MUTATIONS

Figure 1. APC somatic alterations in FAP adenomas. (A) $\mathrm{LOH}$ was assessed in the APC gene by analysing three different markers. Representative example of complete loss of one APC allele (upper panel) and partial loss of another marker (lower panel). (B) Germline and somatic mutations in the APC gene. Schematic representation of the gene, where germline mutations are represented as wide bars and somatic mutations are represented as narrow bars. The MRC (mutation cluster region) region of the gene was screened for mutations in ten adenomas from each of the six FAP patients with known germline mutation. (C) APC relative mRNA levels in FAP and sporadic CRC samples. APC mRNA levels were assessed by means of quantitative PCR. FAP cases (mean value of all samples) were compared with a pool of ten sporadic CRC normal mucosae. The last two bars correspond to the mean values of the ten adenomas and carcinomas compared with their corresponding normal mucosa with minor changes in APC RNA expression.

superfamily, member 11], JAG1 (jagged 1), NKX2-2 (NK2 homeobox 2), WISP2 (WNT1 inducible signalling pathway protein 2), MMP9 (matrix metalloproteinase 9), and SALLA (sal-like 4). The Wnt genes found in frequently lost regions were SMAD4 (SMAD family member 4) and TCF4 (transcription factor 4).

\section{Discussion}

Genetic and epigenetic aberrations in several components of the Wnt signalling pathway have been found, at a high frequency, in colorectal cancers. In this study, we have gained insight into the scope and degree of Wnt pathway activation in APC-driven colorectal tumourigenesis at multiple levels with particular attention to the mRNA expression levels of relevant targets, $\beta$-catenin immunostaining, correlation with KRAS mutations, and the presence of copy number alterations.

A detectable second hit in the APC gene was found in $25 \%$ of APC-FAP adenomas, with LOH being more frequently found than point mutations. Other reports have described a similar rate of $\mathrm{LOH}(21-22 \%)[7,27]$, but our rate of somatic mutations in $A P C$ is lower. The relatively low prevalence of second mutations found may be related to the fact that only the MCR of the gene was analysed, leaving aside a high proportion of the coding region and all adjacent areas. As has been previously reported [7], LOH in FAP adenomas is not associated with loss of genetic material, further indicating that somatic recombination underlies it.

Consistent APC mRNA overexpression was observed in FAP samples, either morphologically normal or adenoma tissue. Our RT-PCR assay targets a common region shared by all $A P C$ isoforms, thus providing an overall assessment of all $A P C$ transcript levels. In contrast, diminished germline dosage of the APC alleles at both the DNA and the RNA level has been associated with the development of FAP [28-32]. However, and in line with our finding, Venesio et al [33] found increased germline expression of an APC mRNA isoform in AFAP patients. This observation and our ASE results could point to allele-specific expression of the aberrant and inactive form of APC. Further studies are required to explore whether the normal or the mutant allele is overexpressed. Regardless of whether RNA levels are up-regulated or down-regulated, subtle changes must tend to select a modest, maybe optimal, 
Table 3. KRAS and $\beta$-catenin status in FAP adenomas

\begin{tabular}{|c|c|c|c|c|c|}
\hline \multirow[b]{2}{*}{ Sample } & \multirow[b]{2}{*}{$\begin{array}{c}\text { KRAS somatic } \\
\text { mutation }\end{array}$} & \multicolumn{2}{|c|}{$\beta$-Catenin } & \multirow[b]{2}{*}{$\begin{array}{c}\text { APC biallelic } \\
\text { mutation }\end{array}$} & \multirow[b]{2}{*}{$\begin{array}{c}\text { FAP adenoma } \\
\text { size }\end{array}$} \\
\hline & & Cytoplasm & Nucleus & & \\
\hline FAP4 AD5 & - & ++ & +++ & $\mathrm{LOH}$ & Large \\
\hline FAP4 AD10 & - & ++ & +++ & $\mathrm{LOH}$ & Medium \\
\hline FAP4 AD7 & - & ++ & +++ & - & Medium \\
\hline FAP4 AD8 & - & + & +++ & $\mathrm{LOH}$ & Small \\
\hline FAP4 AD9 & - & ++ & +++ & - & Small \\
\hline FAP8 AD9 & - & ++ & +++ & - & Small \\
\hline FAP8 AD8 & - & ++ & +++ & - & Small \\
\hline FAP1 AD4 & - & ++ & ++ & $\mathrm{LOH}$ & Large \\
\hline FAP1 AD2 & $G 12 A G>C$ & + & ++ & $\mathrm{LOH}$ & Large \\
\hline FAP1 AD5 & - & + & ++ & $\mathrm{LOH}$ & Large \\
\hline FAP1 AD7 & - & ++ & ++ & $\mathrm{LOH}$ & Large \\
\hline FAP1 AD3 & - & + & ++ & - & Small \\
\hline FAP1 AD6 & - & ++ & ++ & $\mathrm{LOH}$ & Large \\
\hline FAP1 AD1 & - & ++ & ++ & - & Small \\
\hline FAP3 AD5 & - & +++ & ++ & - & Medium \\
\hline FAP3 AD6 & - & ++ & ++ & - & Large \\
\hline FAP4 AD4 & - & ++ & ++ & - & Large \\
\hline FAP4 AD3 & - & + & ++ & - & Small \\
\hline FAP6 AD6 & - & + & ++ & - & Small \\
\hline FAP6 AD4 & - & ++ & ++ & - & Small \\
\hline FAP6 AD3 & - & ++ & ++ & - & Small \\
\hline FAP6 AD2 & - & +++ & ++ & - & Small \\
\hline FAP8 AD5 & - & + & ++ & - & Small \\
\hline FAP8 AD10 & - & + & ++ & - & Small \\
\hline FAP8 AD7 & - & + & ++ & E1397X & Small \\
\hline FAP8 AD6 & - & + & ++ & - & Small \\
\hline FAP9 AD3 & - & +++ & ++ & $\mathrm{LOH}$ & Small \\
\hline FAP1 AD8 & - & ++ & $+1-$ & - & Small \\
\hline FAP1 AD9 & - & ++ & $+1-$ & - & Small \\
\hline FAP3 AD7 & $\mathrm{G} 12 \mathrm{D} G>\mathrm{A}$ & ++ & + & - & Small \\
\hline FAP3 AD8 & - & ++ & + & - & Medium \\
\hline FAP3 AD9 & - & ++ & + & - & Small \\
\hline FAP3 AD10 & - & ++ & + & - & Small \\
\hline FAP4 AD1 & - & ++ & + & - & Small \\
\hline FAP4 AD2 & - & + & + & - & Small \\
\hline FAP6 AD7 & - & ++ & + & $\mathrm{LOH}$ & Small \\
\hline FAP6 AD1 & - & ++ & + & - & Small \\
\hline FAP6 AD5 & - & + & + & - & Small \\
\hline FAP6 AD8 & - & ++ & + & $\mathrm{LOH}$ & Small \\
\hline FAP6 AD9 & - & ++ & + & - & Small \\
\hline FAP6 AD10 & - & + & + & - & Small \\
\hline FAP8 AD4 & - & + & + & - & Small \\
\hline FAP8 AD3 & $\mathrm{G} 12 \mathrm{D} G>A$ & ++ & + & - & Small \\
\hline FAP9 AD2 & - & ++ & + & - & Small \\
\hline FAP3 AD3 & $\mathrm{G} 12 \mathrm{~S} \mathrm{G}>\mathrm{A}$ & ++ & $-1+$ & - & Small \\
\hline FAP3 AD2 & - & + & $-1+$ & $01338 x$ & Small \\
\hline FAP1 AD10 & - & + & - & - & Small \\
\hline FAP3 AD1 & $\mathrm{G} 12 \mathrm{C} \mathrm{G}>\mathrm{T}$ & ++ & - & - & Large \\
\hline FAP3 AD4 & - & - & - & - & Medium \\
\hline FAP8 AD2 & - & - & - & - & Small \\
\hline FAP8 AD1 & - & + & - & - & Small \\
\hline FAP9 AD9 & - & ++ & - & - & Small \\
\hline FAP9 AD10 & - & ++ & - & - & Small \\
\hline FAP9 AD8 & - & - & - & - & Small \\
\hline FAP9 AD6 & - & + & - & - & Small \\
\hline FAP9 AD7 & $\mathrm{G} 12 \mathrm{~A} G>C$ & + & - & - & Small \\
\hline FAP9 AD4 & - & + & - & - & Small \\
\hline FAP9 AD1 & - & + & - & S1356X & Small \\
\hline FAP9 AD5 & - & - & - & E1309X & Small \\
\hline FAP4 AD6 & - & & & - & Large \\
\hline
\end{tabular}

$-=$ no mutation/no staining; $+=$ weak staining; $++=$ moderate staining; $+++=$ strong staining. 


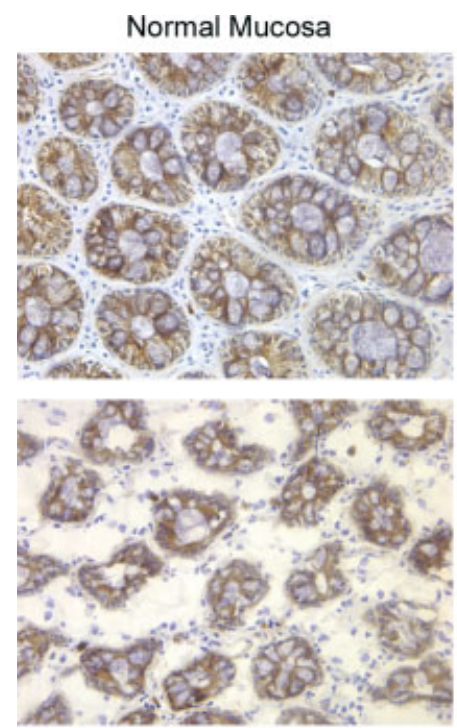

Normal Mucosa
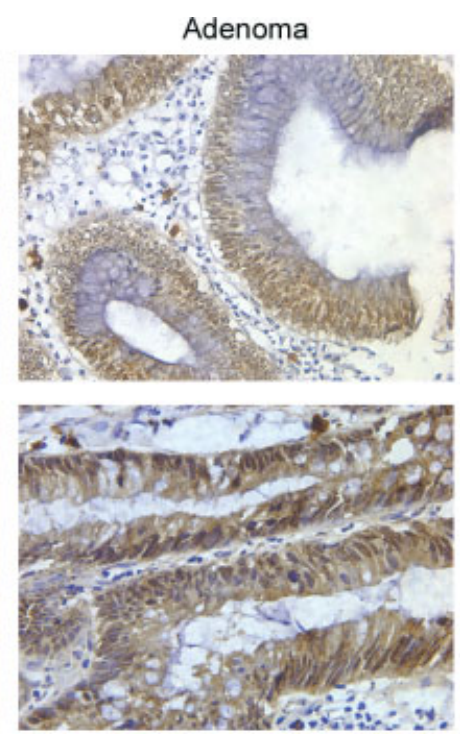

Adenoma
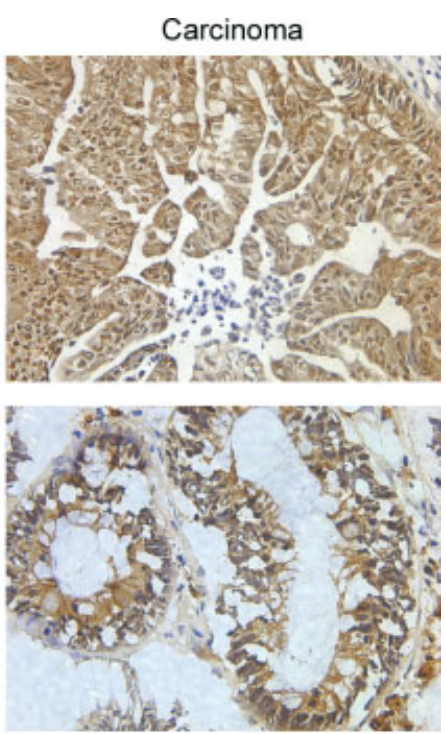

Adenoma

Figure 2. $\beta$-Catenin translocates to the nucleus in colorectal tumour samples. $\beta$-Catenin immunostaining of normal mucosa, an adenoma, and a carcinoma of sporadic colorectal cancer patients representative of all samples (upper panel). $\beta$-Catenin immunostaining of normal mucosa and two different adenomas of FAP patients representative of all samples (lower panel). $\beta$-Catenin is restricted to the cytoplasm in normal samples, whereas it accumulates in the cytoplasm and translocates to the nucleus in tumour samples.

APC expression level for FAP adenoma development. Our observations also indicate that this mRNA deregulation is not present in sporadic CRC samples, suggesting a different mechanism of Wnt activation and reinforcing the role of the first $A P C$ hit in FAP that not only influences the molecular nature of the second hit, but might also influence the level of $A P C$ mRNA expression.

Nuclear $\beta$-catenin immunostaining has been considered a surrogate of Wnt pathway activation that would occur upon homozygous loss of APC. Previous studies assessing nuclear $\beta$-catenin in FAP adenomas yielded controversial findings showing both positive [34,35] and negative results [20,36-38]. Discrepancies have been attributed to the technical challenges associated with $\beta$-catenin staining. Using an immunohistochemical technique that yielded consistent results both in fresh-frozen and in paraffin-embedded tissues, we detected some degree of nuclear immunostaining in $80 \%$ of the fresh-frozen FAP adenomas analysed. In a recent report, Phelps et al combined zebrafish, in vitro studies, and tumour analyses to conclude that loss of APC alone stabilizes the levels of cytoplasmic $\beta$-catenin but this stabilization is insufficient for causing $\beta$-catenin nuclear accumulation, which requires the activities of KRAS and RAF1 [20]. Our results not only confirm the APC-associated cytoplasmic accumulation of $\beta$-catenin, but also show that biallelic APC inactivation is strongly associated with moderate or strong nuclear staining, supporting the idea that APC total inactivation is driving and increasing Wnt signalling activation. In line with previous reports [39], a low prevalence of $K R A S$ mutations was found. Importantly, no apparent relationship was observed with $\beta$-catenin nuclear accumulation. Thus, our results conflict with those of Phelps et al, showing that FAP adenomas with mono- or bi-allelic $A P C$ inactivation and without KRAS mutations are capable of inducing $\beta$-catenin nuclear translocation. While several animal models have demonstrated that KRAS mutation enhances the APC inactivation effect [40-49], the involvement of $K R A S$ in $\beta$-catenin nuclear localization remains to be elucidated.

The Wnt pathway regulates development and cellular homeostasis and is well conserved through evolution. If early pathway activation is present, regulation of other members of the signalling pathway should occur. MYC was first described as a target of the Wnt pathway [50] and has been identified as a key effector of the $\beta$-catenin transcriptional programme [51]. MYC levels were up-regulated in the majority of adenomas and carcinomas, and correlated with $\beta$-catenin nuclear immunostaining. AXIN2 was also overexpressed in FAP adenomas, in line with previous reports [52,53]. AXIN2 overexpression can be used as a surrogate of Wnt signalling activation since it serves as a negative feedback loop for the Wnt signalling pathway [54]. Although AXIN2 overexpression can down-regulate $\beta$-catenin in human tumour cell lines $[54,55]$, a destruction complex with an inactive APC component is apparently not capable of eliminating $\beta$ catenin accumulation in FAP adenomas.

In agreement with previous reports [52,56], SFRPI was consistently down-regulated or even undetectable in FAP and sporadic tumours. SFRP1 is a member of the SFRP family of proteins that act as inhibitors of Wnt signalling by preventing binding to its receptor. In normal Wnt signalling, SFRP1 levels are regulated by $\beta$-catenin/TCF4 and promoter methylation is suggested by some authors as the mechanism by which SFRP transcription is inactivated [52,57]. In APC-driven tumourigenesis, SFRP1 down-regulation is a very early 
A
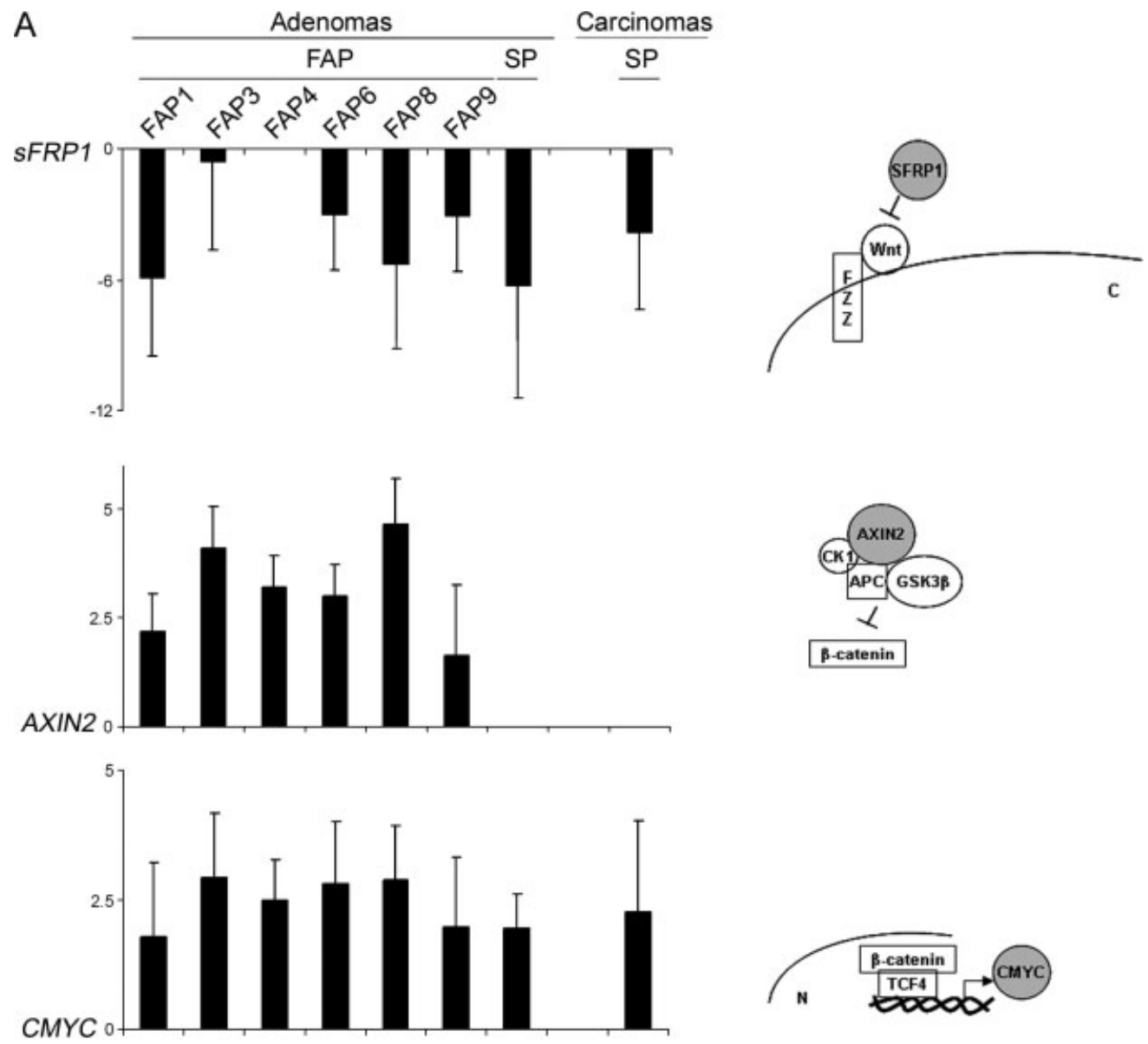

\section{B}

\begin{tabular}{lllllll}
\hline \multicolumn{2}{c}{ C-MYC } & \multicolumn{2}{c}{ sFRP1 } & \multicolumn{2}{c}{ AXIN2 } \\
\hline & log ratio & $p$-value & log ratio & $p$-value & log ratio & $p$-value \\
\hline PCF1 & 1.78 & $0.019^{\star}$ & -24.16 & $0.002^{\star *}$ & 2.18 & $0.002^{\star *}$ \\
PCF3 & 2.92 & $0.002^{* *}$ & -18.85 & 0.064 & 4.11 & $0.002^{\star *}$ \\
PCF4 & 2.48 & $0.002^{* *}$ & ND & ND & 3.21 & $0.002^{* *}$ \\
PCF6 & 2.82 & $0.002^{* *}$ & -27.39 & $0.002^{\star *}$ & 2.99 & $0.002^{\star *}$ \\
PCF8 & 2.87 & $0.002^{* *}$ & -17.46 & $0.006^{\star *}$ & 4.65 & $0.002^{* *}$ \\
PCF9 & 1.98 & $0.002^{* *}$ & -3.06 & 0.084 & 1.62 & $0.013^{*}$ \\
\hline
\end{tabular}

ND: non-detectable

Figure 3. Altered expression levels of Wht signalling members in colorectal tumour samples. (A) Relative RNA expression levels of SFRP1, $A X I N 2$, and CMYC expressed as $\log _{2}$ ratios (0 means no change). Mean values of the ten adenomas from the six FAP patients and mean values of ten sporadic (SP) colorectal cancer adenomas and carcinomas compared with their corresponding normal mucosa. Schematic representation of the protein function and location. SFRP1 binds to Frizzled (FZZ) receptors and prevents Wnt binding, and thus inhibits the pathway. AXIN2 is part of the $\beta$-catenin destruction complex and promotes $\beta$-catenin degradation by the proteasome. MYC is a target of the pathway and it promotes cell proliferation. (B) $\log _{2}$ ratio expression and $p$ value for the three genes. ${ }^{*} p<0.05$; ${ }^{* *} p<0.01$.

event that may promote further deregulation of the Wnt pathway.

The abnormal expression of MYC and SFRPI in the macroscopically normal mucosa in patients with FAP provides us with indirect evidence that the Wnt pathway is already activated in the very early stages of tumourigenesis. Previously, we have shown that overexpression of mitotic checkpoint proteins is present in both adenomas and normal mucosa from FAP patients [9]. Overall, our results point to an evident functional impact of a single $A P C$ mutated allele and our data are consistent with results obtained by Yeung et al using protein analysis techniques in normal colon crypts from FAP patients [58].

When we expanded our Wnt signalling pathway analysis to the DNA level, the combined analysis of FAP adenomas, sporadic adenomas, and carcinomas led to the observation that Wnt pathway components and target genes are overrepresented in areas with losses and gains, supporting the third-hit hypothesis where Wnt signalling modulation could be secondary to copy number changes in more advanced stages of tumour 


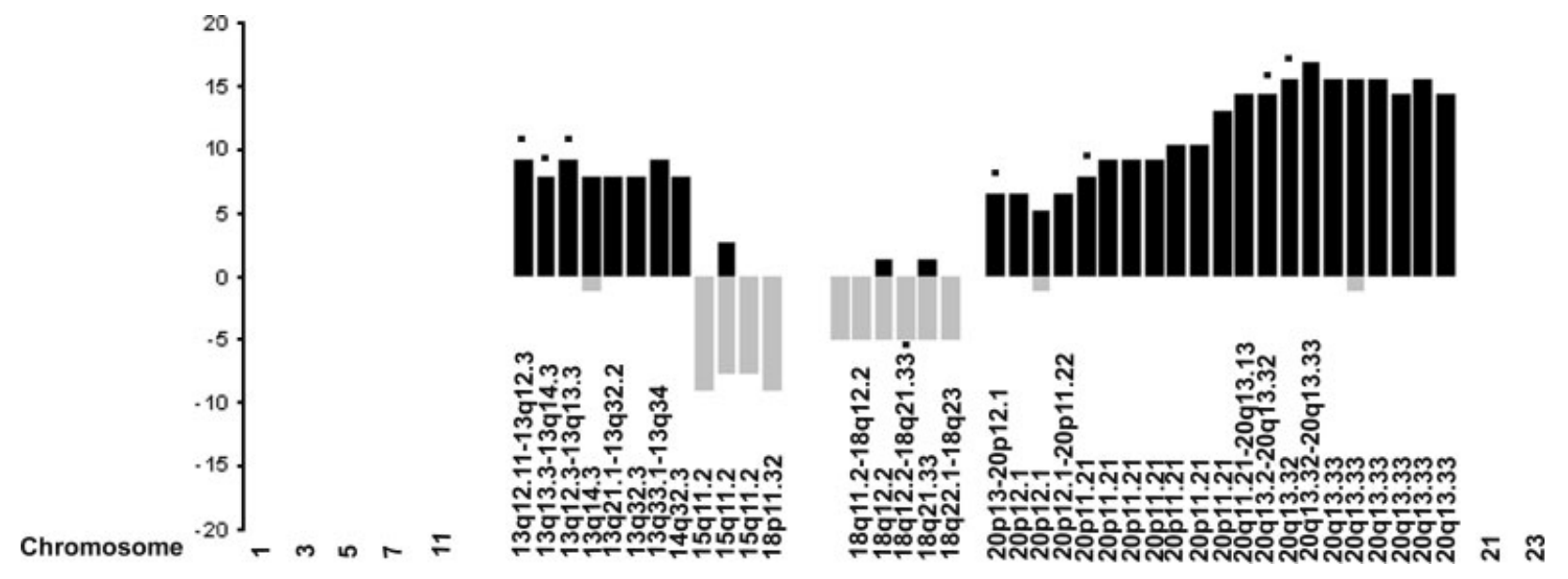

Figure 4. Array CGH data of colorectal tumours. Array CGH data are represented as a bar plot, where gains are shown in black and losses in grey. The $Y$ axis represents the percentage of samples that harbour the change in copy number. Regions containing Wnt genes are marked with a dot.

progression [8]. Some of these Wnt genes, such as $J A G 1$, a key member of the Notch signalling pathway [59], and POSTN [60], have been previously described to be altered in CRC. Our aCGH data further extend published results in APC- and MYH-FAP adenomas $[61,62]$ and show that adenomas harbour a low level of genetic instability.

Taken together, our results suggest that monoallelic $A P C$ mutation might be sufficient for deregulation of the expression of $A P C$ and other key members of the Wnt pathway. While $A P C$ biallelic inactivation is associated with $\beta$-catenin nuclear localization, KRAS mutations do not appear to be necessary for this translocation. The data presented here further elucidate the mechanisms of APC-driven tumourigenesis. Early and universal transcriptional activation of the Wnt signalling pathway is evident at the RNA level, whilst further activation may occur later as genomic instability supervenes and copy number variations then arise. We have identified novel loci of genomic instability that may direct further investigation of potentially novel genes relevant to colorectal cancer genes.

\section{Acknowledgment}

AO-H dedicates this study to her father, the late $\mathrm{Dr}$ Antoni Obrador, who died in 2006 and who not only inspired this work, but was also very helpful with both samples and advice. We thank Xavi Solé for advice and help in the microarray analysis, Gemma Aiza for technical assistance, and Eric Fearon for helpful discussions and critical reading of the manuscript. This study was supported by grants from the following: Fundació La Caixa, PI: GC (BM05-254-0); Spanish Networks RTICCC (RD06/0020/1050, 1051), Instituto de Salud Carlos III (SAF 2003-08339, SAF 200606084, SAF 2009-07319); Acción Transversal del Cáncer; and Fundació Gastroenterologia Dr Francisco Vilardell.

\section{References}

1. Lipton L, Tomlinson I. The genetics of FAP and FAP-like syndromes. Fam Cancer 2006; 5: 221-226.

2. Azzopardi D, Dallosso AR, Eliason K, Hendrickson BC, Jones N, Rawstorne E, et al. Multiple rare nonsynonymous variants in the adenomatous polyposis coli gene predispose to colorectal adenomas. Cancer Res 2008; 68: 358-363.

3. Menendez M, Gonzalez S, Obrador-Hevia A, Dominguez A, Pujol MJ, Valls J, et al. Functional characterization of the novel APC N1026S variant associated with attenuated familial adenomatous polyposis. Gastroenterology 2008; 134: 56-64.

4. Takayama T, Katsuki S, Takahashi Y, Ohi M, Nojiri S, Sakamaki S, et al. Aberrant crypt foci of the colon as precursors of adenoma and cancer. N Engl J Med 1998; 339: 1277-1284.

5. Lamlum H, Papadopoulou A, Ilyas M, Rowan A, Gillet C, Hanby A, et al. APC mutations are sufficient for the growth of early colorectal adenomas. Proc Natl Acad Sci U S A 2000; 97: 2225-2228.

6. Lamlum H, Ilyas M, Rowan A, Clark S, Johnson V, Bell J, et al. The type of somatic mutation at APC in familial adenomatous polyposis is determined by the site of the germline mutation: a new facet to Knudson's 'two-hit' hypothesis. Nature Med 1999; 5: 1071-1075.

7. Crabtree M, Sieber OM, Lipton L, Hodgson SV, Lamlum H, Thomas HJ, et al. Refining the relation between 'first hits' and 'second hits' at the APC locus: the 'loose fit' model and evidence for differences in somatic mutation spectra among patients. Oncogene 2003; 22: 4257-4265.

8. Segditsas S, Rowan AJ, Howarth K, Jones A, Leedham S, Wright NA, et al. APC and the three-hit hypothesis. Oncogene 2009; 28: 146-155.

9. Abal M, Obrador-Hevia A, Janssen KP, Casadome L, Menendez M, Carpentier S, et al. APC inactivation associates with abnormal mitosis completion and concomitant BUB1B/MAD2L1 upregulation. Gastroenterology 2007; 132: 2448-2458.

10. Gaspar C, Cardoso J, Franken P, Molenaar L, Morreau H, Moslein G, et al. Cross-species comparison of human and mouse intestinal polyps reveals conserved mechanisms in adenomatous polyposis coli (APC)-driven tumorigenesis. Am J Pathol 2008; 172: $1363-1380$.

11. Kaiser S, Park YK, Franklin JL, Halberg RB, Yu M, Jessen WJ, et al. Transcriptional recapitulation and subversion of embryonic colon development by mouse colon tumor models and human colon cancer. Genome Biol 2007; 8: R131. 
12. Reichling T, Goss KH, Carson DJ, Holdcraft RW, Ley-Ebert C, Witte D, et al. Transcriptional profiles of intestinal tumors in Apc(Min) mice are unique from those of embryonic intestine and identify novel gene targets dysregulated in human colorectal tumors. Cancer Res 2005; 65: 166-176.

13. Sabates-Bellver J, Van der Flier LG, de Palo M, Cattaneo E, Maake C, Rehrauer $\mathrm{H}$, et al. Transcriptome profile of human colorectal adenomas. Mol Cancer Res 2007; 5: 1263-1275.

14. Segditsas S, Sieber O, Deheragoda M, East P, Rowan A, Jeffery R, et al. Putative direct and indirect Wnt targets identified through consistent gene expression changes in APC-mutant intestinal adenomas from humans and mice. Hum Mol Genet 2008; 17: 3864-3875.

15. Morin PJ, Sparks AB, Korinek V, Barker N, Clevers H, Vogelstein B, et al. Activation of beta-catenin-Tcf signaling in colon cancer by mutations in beta-catenin or APC. Science 1997; 275: 1787-1790.

16. Behrens J, Jerchow BA, Wurtele M, Grimm J, Asbrand C, Wirtz R, et al. Functional interaction of an axin homolog, conductin, with beta-catenin, APC, and GSK3beta. Science 1998; 280: 596-599.

17. Goss KH, Groden J. Biology of the adenomatous polyposis coli tumor suppressor. J Clin Oncol 2000; 18: 1967-1979.

18. Groden J. Touch and go: mediating cell-to-cell interactions and Wnt signaling in gastrointestinal tumor formation. Gastroenterology 2000; 119: 1161-1164.

19. van de Wetering M, Sancho E, Verweij C, de Lau W, Oving I, Hurlstone A, et al. The beta-catenin/TCF-4 complex imposes a crypt progenitor phenotype on colorectal cancer cells. Cell 2002; 111: $241-250$.

20. Phelps RA, Chidester S, Dehghanizadeh S, Phelps J, Sandoval IT, Rai K, et al. A two-step model for colon adenoma initiation and progression caused by APC loss. Cell 2009; 137: 623-634.

21. Cawkwell L, Bell SM, Lewis FA, Dixon MF, Taylor GR, Quirke P. Rapid detection of allele loss in colorectal tumours using microsatellites and fluorescent DNA technology. $\mathrm{Br} J$ Cancer 1993; 67: 1262-1267.

22. Pfaffl MW. A new mathematical model for relative quantification in real-time RT-PCR. Nucleic Acids Res 2001; 29: e45.

23. van den Ijssel P, Tijssen M, Chin SF, Eijk P, Carvalho B, Hopmans E, et al. Human and mouse oligonucleotide-based array CGH. Nucleic Acids Res 2005; 33: e192.

24. Gentleman RC, Carey VJ, Bates DM, Bolstad B, Dettling M, Dudoit $\mathrm{S}$, et al. Bioconductor: open software development for computational biology and bioinformatics. Genome Biol 2004; 5: R80.

25. Hupe P, Stransky N, Thiery JP, Radvanyi F, Barillot E. Analysis of array CGH data: from signal ratio to gain and loss of DNA regions. Bioinformatics 2004; 20: 3413-3422.

26. Lai WR, Johnson MD, Kucherlapati R, Park PJ. Comparative analysis of algorithms for identifying amplifications and deletions in array CGH data. Bioinformatics 2005; 21: 3763-3770.

27. Albuquerque C, Breukel C, van der Luijt R, Fidalgo P, Lage P, Slors FJ, et al. The 'just-right' signaling model: APC somatic mutations are selected based on a specific level of activation of the beta-catenin signaling cascade. Hum Mol Genet 2002; 11: 1549-1560.

28. Castellsague E, Gonzalez S, Nadal M, Campos O, Guino E, Urioste M, et al. Detection of APC gene deletions using quantitative multiplex PCR of short fluorescent fragments. Clin Chem 2008; 54: 1132-1140.

29. Renkonen ET, Nieminen P, Abdel-Rahman WM, Moisio AL, Jarvela I, Arte S, et al. Adenomatous polyposis families that screen APC mutation-negative by conventional methods are genetically heterogeneous. J Clin Oncol 2005; 23: 5651-5659.
30. Segditsas S, Sieber OM, Rowan A, Setien F, Neale K, Phillips RK, et al. Promoter hypermethylation leads to decreased APC mRNA expression in familial polyposis and sporadic colorectal tumours, but does not substitute for truncating mutations. Exp Mol Pathol 2008; 85: 201-206.

31. Venesio T, Balsamo A, Rondo-Spaudo M, Varesco L, Risio M, Ranzani GN. APC haploinsufficiency, but not CTNNB1 or CDH1 gene mutations, accounts for a fraction of familial adenomatous polyposis patients without APC truncating mutations. Lab Invest 2003; 83: 1859-1866.

32. Yan H, Dobbie Z, Gruber SB, Markowitz S, Romans K, Giardiello FM, et al. Small changes in expression affect predisposition to tumorigenesis. Nature Genet 2002; 30: 25-26.

33. Venesio T, Balsamo A, Sfiligoi C, Fuso L, Molatore S, Ranzani GN, et al. Constitutional high expression of an APC mRNA isoform in a subset of attenuated familial adenomatous polyposis patients. J Mol Med 2007; 85: 305-312.

34. Inomata M, Ochiai A, Akimoto S, Kitano S, Hirohashi S. Alteration of beta-catenin expression in colonic epithelial cells of familial adenomatous polyposis patients. Cancer Res 1996; 56: 2213-2217.

35. Takayama T, Ohi M, Hayashi T, Miyanishi K, Nobuoka A, Nakajima T, et al. Analysis of K-ras, APC, and beta-catenin in aberrant crypt foci in sporadic adenoma, cancer, and familial adenomatous polyposis. Gastroenterology 2001; 121: 599-611.

36. Anderson CB, Neufeld KL, White RL. Subcellular distribution of Wnt pathway proteins in normal and neoplastic colon. Proc Natl Acad Sci U S A 2002; 99: 8683-8688.

37. Blaker H, Scholten M, Sutter C, Otto HF, Penzel R. Somatic mutations in familial adenomatous polyps. Nuclear translocation of beta-catenin requires more than biallelic APC inactivation. Am J Clin Pathol 2003; 120: 418-423.

38. Kobayashi M, Honma T, Matsuda Y, Suzuki Y, Narisawa R, Ajioka $\mathrm{Y}$, et al. Nuclear translocation of beta-catenin in colorectal cancer. Br J Cancer 2000; 82: 1689-1693.

39. Miyaki M, Seki M, Okamoto M, Yamanaka A, Maeda Y, Tanaka K, et al. Genetic changes and histopathological types in colorectal tumors from patients with familial adenomatous polyposis. Cancer Res 1990; 50: 7166-7173.

40. Calcagno SR, Li S, Colon M, Kreinest PA, Thompson EA, Fields AP, et al. Oncogenic K-ras promotes early carcinogenesis in the mouse proximal colon. Int J Cancer 2008; 122: 2462-2470.

41. Guerra C, Mijimolle N, Dhawahir A, Dubus P, Barradas M, Serrano $\mathrm{M}$, et al. Tumor induction by an endogenous $\mathrm{K}$-ras oncogene is highly dependent on cellular context. Cancer Cell 2003; 4: $111-120$.

42. Haigis KM, Kendall KR, Wang Y, Cheung A, Haigis MC, Glickman JN, et al. Differential effects of oncogenic K-Ras and N-Ras on proliferation, differentiation and tumor progression in the colon. Nature Genet 2008; 40: 600-608.

43. Janssen KP, Abala M, El Marjou F, Louvard D, Robine S. Mouse models of K-ras-initiated carcinogenesis. Biochim Biophys Acta 2005; 1756: $145-154$.

44. Janssen KP, Alberici P, Fsihi H, Gaspar C, Breukel C, Franken P, et al. APC and oncogenic KRAS are synergistic in enhancing Wnt signaling in intestinal tumor formation and progression. Gastroenterology 2006; 131: 1096-1109.

45. Janssen KP, el-Marjou F, Pinto D, Sastre X, Rouillard D, Fouquet $\mathrm{C}$, et al. Targeted expression of oncogenic K-ras in intestinal epithelium causes spontaneous tumorigenesis in mice. Gastroenterology 2002; 123: 492-504.

46. Johnson L, Mercer K, Greenbaum D, Bronson RT, Crowley D, Tuveson DA, et al. Somatic activation of the K-ras oncogene causes early onset lung cancer in mice. Nature 2001; 410: 1111-1116. 
47. Luo F, Brooks DG, Ye H, Hamoudi R, Poulogiannis G, Patek CE, et al. Mutated K-ras(Asp12) promotes tumourigenesis in Apc(Min) mice more in the large than the small intestines, with synergistic effects between K-ras and Wnt pathways. Int J Exp Pathol 2009; 90: $558-574$.

48. Sansom OJ, Meniel V, Wilkins JA, Cole AM, Oien KA, Marsh V, et al. Loss of Apc allows phenotypic manifestation of the transforming properties of an endogenous K-ras oncogene in vivo. Proc Natl Acad Sci U S A 2006; 103: 14122-14127.

49. Tuveson DA, Shaw AT, Willis NA, Silver DP, Jackson EL, Chang S, et al. Endogenous oncogenic K-ras(G12D) stimulates proliferation and widespread neoplastic and developmental defects. Cancer Cell 2004; 5: 375-387.

50. He TC, Sparks AB, Rago C, Hermeking H, Zawel L, da Costa LT, et al. Identification of c-MYC as a target of the APC pathway. Science 1998; 281: 1509-1512.

51. Sansom OJ, Meniel VS, Muncan V, Phesse TJ, Wilkins JA, Reed KR, et al. Myc deletion rescues Apc deficiency in the small intestine. Nature 2007; 446: 676-679.

52. Caldwell GM, Jones CE, Taniere P, Warrack R, Soon Y, Matthews GM, et al. The Wnt antagonist sFRP1 is downregulated in premalignant large bowel adenomas. $\mathrm{Br} J$ Cancer 2006; 94: 922-927.

53. Yan D, Wiesmann M, Rohan M, Chan V, Jefferson AB, Guo L, et al. Elevated expression of axin2 and hnkd mRNA provides evidence that Wnt/beta-catenin signaling is activated in human colon tumors. Proc Natl Acad Sci U S A 2001; 98: 14973-14978.

54. Lustig B, Jerchow B, Sachs M, Weiler S, Pietsch T, Karsten U, et al. Negative feedback loop of Wnt signaling through upregulation of conductin/axin2 in colorectal and liver tumors. Mol Cell Biol 2002; 22: 1184-1193.
55. Hughes TA, Brady HJ. Regulation of axin2 expression at the levels of transcription, translation and protein stability in lung and colon cancer. Cancer Lett 2006; 233: 338-347.

56. Caldwell GM, Jones C, Gensberg K, Jan S, Hardy RG, Byrd P, et al. The Wnt antagonist sFRP1 in colorectal tumorigenesis. Cancer Res 2004; 64: 883-888.

57. Suzuki H, Watkins DN, Jair KW, Schuebel KE, Markowitz SD, Dong Chen W, et al. Epigenetic inactivation of SFRP genes allows constitutive WNT signaling in colorectal cancer. Nature Genet 2004; 36: 417-422.

58. Yeung AT, Patel BB, Li XM, Seeholzer SH, Coudry RA, Cooper HS, et al. One-hit effects in cancer: altered proteome of morphologically normal colon crypts in familial adenomatous polyposis. Cancer Res 2008; 68: 7579-7586.

59. Rodilla V, Villanueva A, Obrador-Hevia A, Robert-Moreno A, Fernandez-Majada V, Grilli A, et al. Jagged1 is the pathological link between Wnt and Notch pathways in colorectal cancer. Proc Natl Acad Sci U S A 2009; 106: 6315-6320.

60. Bao S, Ouyang G, Bai X, Huang Z, Ma C, Liu M, et al. Periostin potently promotes metastatic growth of colon cancer by augmenting cell survival via the Akt/PKB pathway. Cancer Cell 2004; 5: 329-339.

61. Cardoso J, Molenaar L, de Menezes RX, van Leerdam M, Rosenberg C, Moslein G, et al. Chromosomal instability in MYHand APC-mutant adenomatous polyps. Cancer Res 2006; 66: 2514-2519.

62. Jones AM, Thirlwell C, Howarth KM, Graham T, Chambers W, Segditsas S, et al. Analysis of copy number changes suggests chromosomal instability in a minority of large colorectal adenomas. J Pathol 2007; 213: 249-256.

\section{SUPPORTING INFORMATION ON THE INTERNET}

The following supporting information may be found in the online version of this article.

Table S1. Summary of the results obtained with FAP and CRC samples.

Table S2. Primer sequences used for mutation detection, LOH detection, and quantitative PCR analysis.

Supplementary array data. aCGH raw data for sporadic colorectal cancer samples marked as AD for adenomas and CA for carcinomas. 